\title{
Suicide Terrorism and the Backlash Effect*
}

\author{
B. Peter Rosendorff \\ Department of Politics \\ New York University \\ 19 West $4^{\text {th }}$ St., $2^{\text {nd }}$ Floor \\ New York, NY 10012 \\ peter.rosendorff@nyu.edu \\ Todd Sandler \\ School of Economic, Political \& Policy Sciences \\ University of Texas at Dallas \\ 800 W. Campbell Road \\ Richardson, TX 75080-3021 \\ tsandler@utdallas.edu \\ Phone 1-972-883-6725 \\ Fax 1-972-883-6486
}

February 2010

\begin{abstract}
This paper presents a game-theoretic model of suicide terrorism containing three agents: the terrorist leader, a targeted government, and potential terrorist supporters. Supporters join the terrorist group if they gain more from their participation than from their economic opportunities. Preemptive measures by the government can result in a backlash that encourages recruitment through new grievances. Suicide attacks can also lead to recruitment. Increases in preemption costs and/or economic opportunities can reduce the overall level of terrorism, while increasing the proportion of suicide to normal attacks. An increase in the effect of preemption on recruitment, or the propaganda effect of suicide bombings has the opposite effect of increasing normal and suicide attacks, but decreasing the proportion of suicide to normal attacks in the terrorist organization's strategy profile.
\end{abstract}

Keywords: Backlash; Suicide terrorism; Game theory; Preemption; Terrorism; Recruitment; Mobilization.

JEL Codes: D74, C72, H56

*Rosendorff is an Associate Professor of Politics; Sandler is the Vibhooti Shukla Professor of Economics and Political Economy. This study was funded by the US Department of Homeland Security (DHS) through the Center for Risk and Economic Analysis of Terrorism Events (CREATE) at the University of Southern California, grant number 2007-ST-061-000001. However, any opinions, finding, conclusions, or recommendations are solely those of the authors and do not necessarily reflect the views of DHS or CREATE. Thanks to Leslie Johns for useful comments. 


\section{INTRODUCTION}

Suicide terrorism involves attacks (e.g., bombings, assassinations, or skyjackings) to achieve a political or social objective, in which the perpetrator intends to be sacrificed for the cause (see, e.g., Bloom 2005; Pedahzur 2005). As in other terrorist acts, the terrorist mission is meant to intimidate a wider audience, beyond that of the immediate victims, for the purpose of securing a political objective. Suicide terrorism can be more effective than conventional terrorist attacks at creating an atmosphere of fear, because suicide incidents are, on average, twelve times more lethal with many more horrific injuries (Pape 2005).

Suicide attacks, much more so than more "normal" or conventional attacks, also have two important consequences for the mobilization of potential sympathizers and the emergence of terrorist operatives. Suicide attacks generate reprisals from the target government, which may increase anger and resentment among the potential sympathizers in the population; and the suicide attack itself produces a propaganda effect that may inspire further support for the terrorist organization and its aims. These two effects have a significant impact on the political and economic support for the terrorist organization, and enhance the ability of the organization to generate recruits for further terrorist activities. In this paper, we show that when this "backlash effect" is considered as part of the terrorist leadership's decision calculus, the effects of enhanced preemption can increase the proportion of suicide to normal attacks in the terrorist organization's strategy profile.

The use of suicide terrorism can be traced back to the Jewish Zealots and Sicarii during the first century A.D. (Bloom 2005: 4). These individuals systematically targeted the occupying Romans or their collaborators in Jerusalem. Sicarii operatives used a small dagger in crowded venues, where the assassins had little opportunity to escape. In the modern era of terrorism, suicide terrorism began with Hezbollah's near-simultaneous truck bombings of the US Marine 
barracks and the French Paratroopers sleeping quarters in Beirut on October 23, 1983. The huge blast at the Marine barracks at the Beirut International Airport created a crater 30 feet deep and 120 feet across and caused the four-story building to implode, killing 241 American servicemen and injuring over 80 (Mickolus et al. 1989: 451). The bomb at the apartment building housing 110 French Paratroopers killed 58 soldiers and injured at least 15 others. These attacks resulted in the subsequent withdrawal of the Multinational Forces from Lebanon, as intended by Hezbollah (Pape 2005; Pedahzur 2005). A subsequent suicide terrorist campaign leveled against Israeli forces in Lebanon eventually led to the Israelis leaving Lebanon as demanded. Current and past terrorists saw that suicide attacks quickly achieved political demands. Once these concessions were witnessed, suicide attacks have been part of the terrorist landscape.

Other high-profile and significant suicide terrorist attacks followed including: the suicide assassination of Rajiv Gandhi at Sriperumbudur on May 24, 1991; the simultaneous suicide truck bombings of the US embassies in Nairobi, Kenya and Dar es-Salaam, Tanzania on August 7, 1998; the suicide bombing of the USS Cole in Aden, Yemen on October 12, 2000; and the four hijackings in Boston, Newark, and Washington, DC on September 11, 2001 (henceforth, 9/11). Suicide terrorist campaigns characterized the Second Intifada in Israel, the Tamil Tigers' struggle in Sri Lanka, the Chechen terrorist attacks in Russia, the Kurdistan Workers' Party (PKK) resistance in Turkey, and the insurgency in Iraq. Since 1983, a partial list of terrorist groups using suicide terrorism includes al-Qaida, Hezbollah, Hamas, Palestinian Islamic Jihad, Fatah, the Popular Front for the Liberation of Palestine (PFLP), PKK, Liberation Tigers of Tamil Eelam (LTTE), and Lashkar-e-Taiba (Bloom 2005). Suicide terrorism has been used by both fundamentalist and ethno-separatist terrorists in recent years.

The primary purpose of this paper is to formulate a two-stage game of suicide terrorism involving a terrorist leader, a targeted government, and (potential) terrorist supporters to examine 
the effects of increased preemption efforts on the mix of normal and suicide attacks adopted by an objective-minded rational terrorist organization. We are particularly interested in the comparative statics, tied to changes in the preemption costs of the government, the backlash response by potential terrorist supporters, and the economic opportunities of the terrorists. The backlash arises when heavy-handed proactive or preemptive measures of the government create new grievances and increase support for the terrorists (Arce and Sandler 2010; Bloom 2005: 118-119; Bueno de Mesquita and Dixon 2007; de Figueiredo and Weingast 2001; Gupta and Mundra 2005; Jacobson and Kaplan 2007; Jaeger et al. 2008; Kaplan et al. 2005: 225; Pedahzur 2005: 32-33; Rosendorff and Sandler 2004). Thus, our model contains the three essential agents and the important backlash effect.

The standard approach in the literature is to investigate the effect of deterrence or preemption on the levels of attacks (both normal and suicide) and, perhaps, on the choice of targets. Here, we add a new dimension - the backlash effect. Both preemption and suicide attacks themselves generate sympathy among the population for the terrorists' objectives, and increase the number of available sympathizers that the terrorist organization can then recruit.

The elements of the backlash effect are these: first, government actions that defend against potential attacks - preemption - generate hostility and opposition amongst the population against which the preemption is targeted. For instance, Jaeger et al. (2008) show that Israeli violence against the Palestinians during the Second Intifada swayed Palestinian public opinion to support more radical groups and retaliatory actions. Government response to actual or threatened terrorist attacks mobilizes the populace in support of the terrorist aims and ambitions.

Second, suicide attacks themselves - described as "martyr operations" by the terrorist organizations - generate support amongst the population for the organization's operations. The operations are often associated with video tapes of the perpetrators before the event; videos of 
the operations themselves, and both are often posted on the internet and reach a wide audience via the media. These generate enormous publicity and propaganda victories for the organization. The deed generates supporters for the cause via a propaganda effect. We model this as suicide attacks increasing sympathy for and increasing the number of sympathizers from which operatives can be drawn for all kinds of terrorist operations. ${ }^{1}$

Consequently, rather than simply choosing strategy and target in order to maximize damage, or to further the long-term objectives of the terrorist organization, the terrorist leadership must also consider the effect of their own actions (and the induced response from the government) on the degree of sympathy within the population and, hence, on the resource constraint facing the terrorist organization. This interaction between the actions of the two players - the terrorists and the government - taking account of the backlash effect is the focus of this approach. We examine not only the levels or numbers of attacks, but also the choice of the portfolio of types of attacks when this backlash effect is taken into account. In so doing, a number of interesting, and somewhat unexpected, results emerge.

First, consider the marginal effect of preemption efforts in generating sympathy for the terrorists. The greater is the effect of government action (preemption) on building sympathy and recruits from the population, the larger will be the number of available recruits (and they will be of higher quality) and, hence, the larger is the number of both kinds of attacks. More surprising, however, is that the government is in some sense doing the terrorist organization's work for them in facilitating recruitment - the terrorist organization is less concerned about generating recruits, and can therefore allocate less resources to suicide attacks, instead choosing more normal attacks. There is a substitution away from suicide attacks, thereby increasing the proportion of normal to suicide attacks.

Second, as the marginal costs of preemption rise, there is an overall decline in terrorism. 
This too is somewhat surprising. As the costs of preemption rise, there will of course be less preemption activity. This effect would, intuitively, raise the level of overall terrorist activity; however, less preemption reduces the number of available recruits, tightening the resource constraint that the terrorist organization faces. This resource constraint effect binds more tightly than the reduced preemption effect on the likelihood of success of any attack, and hence, the overall effect is a decline in terrorism overall. However, the terrorist organization, eager to increase the number of available recruits now that the constraint is binding more tightly, will choose to engage more suicides relative to normals in order to counter the lower incentives within the population to volunteer. There is, therefore, a mixed blessing since the proportion of the more deadly suicide attacks increases.

Finally, if wages in the formal economy rise, the opportunity costs of terrorist activity go up. This makes the population less inclined to volunteer, shrinking the resource constraint facing the terrorist leadership. As before, this leads to a decline in both kinds of terrorist attacks. Once again, however, the terrorist leadership will attempt to mitigate this shrinkage in volunteers by engaging in more suicide attacks relative to normals in order to take advantage of the backlash effect. Unlike suicide attacks, normal attacks do not result in a backlash.

This paper also makes a contribution to the politics of terrorist organizations. Terrorist action and suicide attacks, in particular, affect the degree of political support among the population for the aims and objectives of the radical group. Consequently, models that simply focus on the conflict between the radicals and the government miss a crucial aspect of the decision-making process within terrorist organizations. Recent scholarship has begun to take fractionalization within terrorist organizations as a focus of research efforts; for example, Bueno de Mesquita $(2005,2008)$ explores how counterterrorism in the presence of fractionalization can generate more violence, increased radicalization, and government concessions. But no previous 
analysis explores the interaction between counterterrorism and suicide attacks in the presence of the backlash effect.

The remainder of the paper contains four sections. The next section indicates preliminaries and reviews the relevant literature. The game-theoretic model is then presented in the ensuing section, followed by the comparative statics in the third section. The final section contains concluding remarks.

\section{PRELIMINARIES}

Terrorists seek political concessions through extortion based on violence. Particularly deadly terrorist attacks not only give terrorists publicity, but such events also create anxiety in a targeted population. This anxiety can result in popular pressures for a government to concede to terrorist demands, as the newly elected Spanish government did by withdrawing Spanish troops from Iraq after the (non-suicidal) Madrid commuter train bombings on March 11, 2004. Suicide bombings are generally more lethal because the bomber can typically control the place and timing of the explosion to maximize carnage. Thus, a suicide bomber can move to the largest density of people before detonating the device. Pape (2005) and others document that some suicide terrorist campaigns yielded concessions - e.g., the United States left Beirut after the Marine barracks bombing and the United States removed its troops from Saudi Arabia after some alQaida suicide missions.

Throughout history, terrorists have copied and improved effective forms of attacks (Enders and Sandler 2006), and the copying of suicide attacks is no exception to this demonstration effect. Suicide terrorist attacks increased in popularity around 1988 (Pedahzur 2005). These attacks have assumed myriad forms: truck and car bombings, suicide belts, armed attacks, dinghy bombings, and donkey bombings. Any means of transportation can be adapted to 
a suicide mission, as graphically demonstrated by 9/11. In recent years, suicide terrorist attacks have spilled over to Europe - e.g., the July 7, 2005 attacks on the London transportation system. The use of suicide terrorism has been traced to the provision of public goods (Azam 2005; Berman and Laitin 2008), a reaction to excessive government force (Bloom 2005), competition among terrorist groups for public support (Bloom 2005; Pedahzur 2005), and an attempt to break a terrorist-government stalemate (Bloom 2005).

The literature views suicide terrorism as a rational response by the terrorist organization in utilizing its scarce resources to achieve its political agenda (e.g., Arce et al. 2009; Azam 2005; Benmelech and Berrebi 2007; Benmelech et al. 2008; Bloom 2005; Enders and Sandler 2006; Jacobson and Kaplan 2007). If the terrorist group anticipates that the expected gain from the suicide mission exceeds the associated expected costs, including the loss of a trained operative, then the terrorist group will engage in suicide attacks. The rewards include not only possible government concessions, but also recruits if the campaign garners popular support. This support can be enhanced when a stringent proactive response by the besieged government results in popular backlash. Given the associated horrific carnage of suicide bombings, governments can be anticipated, at times, to respond without restraint - a reaction that can assist the terrorists. Terrorist groups can keep their associated costs down by using expendable operatives, where the organization's investment is small. Thus, one seldom sees terrorist leaders or specialists (e.g., bomb makers or strategic planners) engaging in suicide attacks. The literature points out that successful suicide bombings can result in many new recruits (Hoffman 2006: 153), so that the human costs to the terrorist organization may, at times, be negative. Moreover, the actual costs of suicide bombings are small - a Palestinian suicide bombing costs approximately $\$ 150$ in materials (Hoffman 2006: 133). Given the small costs and potential high payoff, the surge in suicide terrorist attacks since the mid-1990s is not surprising. Benmelech and Berrebi (2007) 
show that terrorist leaders rationally assign older and better educated recruits to the more important and challenging suicide missions, so that the organization realizes a greater payback in terms of casualties from its more valuable operatives.

Terrorist operatives are also motivated by their decision calculus. To engage in a mission, an operative must view the expected utility of their sacrificial attack to exceed the expected utility of living. The former expected utility may be bolstered by some or all of the following: rewards in the afterlife (Berman and Laitin 2008); prestige and camaraderie accorded to the bomber (Wintrobe 2006); altruism from the associated intergenerational public good (Azam 2005); and/or payment to the bomber's family (Berman and Laitin 2005). Azam (2005) views the associated public good - i.e., the sought-after political change - as nonexcludable and nonrival, while Berman and Laitin (2008) cast the associated public good - i.e., social services as an excludable club good given to the followers and families. To gain access to these club goods, potential suicide bombers must be members and will make any sacrifice that the leader requests, so that friends and family have access to these club goods which include social services.

In the literature, the agents in a terrorist game of suicide include various combinations: terrorist operatives (Azam 2005; Jain and Mukand 2004); the suicide bomber and the terrorist group's leader (Berman and Laitin 2008); and the government and the terrorist organization (Arce et al. 2009; Enders and Sandler 2004; Jacobson and Kaplan 2007). Wintrobe's (2006) interesting analysis of suicide terrorism includes the terrorist leader and operatives, but in a nonstrategic framework. To date, there is no game-theoretic model of suicide terrorist that includes the terrorist leader, the targeted government, and the terrorist operatives, and that takes account of the backlash effect. The model presented in the next two sections involves these three agents in a framework that determines the mix between normal and suicide attacks. ${ }^{2}$ In addition, 
we allow potential social terrorist recruits to be influenced, in part, by a backlash to harsh proactive measures by the government. These sympathetic volunteers are also impacted by economic opportunities afforded by the economy.

\section{MODEL}

Our game includes two stages. In stage 1, the terrorist leader $(T)$ allocates resources between normal $(n)$ and suicide attacks $(s)$, while the government chooses a level of preemption $(\theta)$ to prevent terrorism. ${ }^{3}$ In stage 2 , potential terrorist supporters in the population of size, $P$, decide whether or not to become terrorists. To find the subgame perfect equilibrium, we solve the game backward, beginning with the choice of the potential terrorist operatives at the second stage. These potential volunteers are influenced by $b(\theta, s) \in[0,1)$, which is a measure of sympathy for the terrorist organization that we call backlash. This sympathy increases with both preemption and suicide missions, so that $b_{\theta}>0$ and $b_{s}>0$. The number of sympathizers, $N$, in population $P$ is less than the total population, in which $N=P b(\theta, s)$.

Each individual (or potential terrorist) in society has a type $\omega_{i} \in \mathbb{R}^{+}$that is distributed continuously over a strictly increasing cumulative distribution function $(c d f)$, denoted by $\Omega(\bullet)$. If potential terrorist $i$ engages in the formal economy, he or she earns $\omega_{i} w$, so that his or her gain is $U_{i}^{e}=\omega_{i} w$, where $w$ is a measure of the aggregate condition of the economy that we can take to be the wage. A potential terrorist decides whether or not to join the group by comparing opportunities in the economy with those in the terrorist organization. To simplify the choice in the model, we normalize the utility from volunteering, $U_{i}^{v}$ to be equal to $1 .{ }^{4}$ Hence, $i$ will volunteer when $U_{i}^{v}>U_{i}^{e}$ or $1>\omega_{i} w$. Then, the fraction of the population or sympathizers who 
volunteers is:

$$
\operatorname{Pr}\left(\frac{1}{w}>\omega_{i}\right)=\Omega\left(\frac{1}{w}\right),
$$

where $\operatorname{Pr}$ denotes probability. The number of volunteers is then $\Omega\left(\frac{1}{w}\right) P b(\theta, s)$ or the fraction of sympathizers, $N$, whose economic opportunities favor being a terrorist. The number of terrorist volunteers constrains the terrorist leader's choice in stage 1 as he allocates these volunteers between normal and suicide missions.

\section{Stage 1}

The terrorist leader maximizes a reward, $R$, from attacking society where $R=R(\theta, s, n)$. This reward decreases with preemption, but increases with either form of terrorism, so that $R_{\theta}<0$, $R_{s}>0$, and $R_{n}>0$. As is standard, we assume diminishing returns with $R_{\theta \theta}>0, R_{s s}<0$, and $R_{n n}<0$. To simplify the analysis, we assume that all cross partials are zero. ${ }^{5}$

The terrorist leader chooses $s$ and $n$ to maximize his net reward,

$$
U^{T}(s, n ; \theta)=R(\theta, s, n)-(n+s)
$$

where the marginal cost of attacks is unity, subject to:

$$
n+s \leq \Omega\left(\frac{1}{w}\right) P b(\theta, s),
$$

which is the total number of volunteers. Assuming an interior solution, the resource constraint can be rewritten as:

$$
n(s)=\Omega\left(\frac{1}{w}\right) P b(\theta, s)-s,
$$

so that we can transform the constrained problem with two choice variables into an equivalent 
unconstrained problem,

$$
\max _{s}\left\{R[\theta, s, n(s)]-\Omega\left(\frac{1}{w}\right) P b(\theta, s)\right\}
$$

with a single choice variable, $s$.

The first-order condition (FOC) is then:

$$
R_{s}+R_{n}\left[\Omega\left(\frac{1}{w}\right) P b_{s}-1\right]-\Omega\left(\frac{1}{w}\right) P b_{s}=0 .
$$

In (6), $R_{s}$ is the marginal benefit from more suicide missions, while the second term on the lefthand side is the opportunity costs from fewer normal attacks and the third term is the marginal costs in terms of operatives. In (6), the term in brackets is $n^{\prime}(s)$, which is the reduction in normal attacks via (3) as the terrorist leader engages in more suicide missions. ${ }^{6}$ The government chooses its preemptive measures in stage 1 to weaken the terrorist organization, so that the latter can less effectively pursue normal or suicide attacks. The costs of preemption, $C(\theta)$, is strictly increasing for all preemption levels. The government's objective is to minimize the sum of its preemptive costs and terrorism-induced losses. This minimizing objective dates back to Sandler and Lapan (1988) in a different counterterrorism context. Terrorism-induced losses are a weighted value of the rewards achieved by the terrorist leader, where the weight $\beta$ is positive. We transform the government's minimum problem into the following:

$$
\max _{\theta}[-C(\theta)-\beta R(\theta, s, n)]
$$

whose FOC is

$$
-C^{\prime}(\theta)-\beta R_{\theta}=0 .
$$

In (8), the marginal benefit of preemption $\left(-\beta R_{\theta}>0\right)$ is set equal to the marginal preemption 
$\operatorname{costs}\left[C^{\prime}(\theta)\right]$.

\section{Subgame perfect equilibrium}

At stage 1, the subgame perfect equilibrium corresponds to a pair of strategies $\{\theta, s\}$ that simultaneously satisfies the FOCs for the government and the terrorist leader - i.e., (8) and (6), respectively - conditioned on the terrorist supporters' choice in stage 2 . This latter optimizing choice is included in the terrorist leader's constrained maximization problem. For the comparative statics, we linearize the backlash and preemption costs functions, so that $b(\theta, s)=b \theta s$ and $C=c \theta$. This gives us the following two FOCs for the comparative statics:

$$
\begin{aligned}
-c-\beta R_{\theta} & =0, \\
R_{s}+R_{n}\left[\Omega\left(\frac{1}{w}\right) P b \theta-1\right]-\Omega\left(\frac{1}{w}\right) P b \theta & =0 .
\end{aligned}
$$

The second-order condition required of this system is satisfied when $-\beta R_{\theta \theta}<0$ and $-\beta R_{\theta \theta}\left[R_{s s}+R_{n n}(\Omega P b-1)^{2}\right]>0$, where the argument in $\Omega(\bullet)$ is suppressed. These conditions are satisfied because $R_{\theta \theta}>0, R_{n n}<0$, and $R_{s s}<0$.

\section{COMPARATIVE STATICS}

Based on the FOCs in (9)-(10), we can derive some comparative statics propositions.

Proposition 1 involves the effects of a change in the marginal costs of preemption, $c$.

Proposition 1: $\frac{\partial \theta}{\partial c}<0 ; \frac{\partial s}{\partial c} \leq 0 ; \frac{\partial n}{\partial c}<0 ;$ and $\frac{\partial(n / s)}{\partial c}<0$.

Proof: see Appendix. 
This result is quite interesting. When the costs of preemption rise, the level of preemption, $\theta$, falls, which agrees with intuition. The drop in preemption has two opposing consequences. First, it reduces the number of sympathizers, which, in turn, limits the number of operatives. As a result, both types of terrorist attacks - suicide and normal - fall. Second, the expected return from any attack increases as preemption activities fall, which encourages more terrorist attacks. The first effect, however, outweighs the second effect (see Appendix) so that we anticipate a reduction in both kinds of attacks. Because the marginal return to the terrorists is higher from suicide than from normal attacks owing to recruitment and backlash, the proportion of normal attacks relative to suicide attacks falls with an increase in $c$-i.e., $\partial(n / s) / \partial c<0$. This proportional increase in suicide attacks is a surprising negative consequence as terrorists position themselves for maximum advantage. Thus, reduced preemption adversely affects the mix of terrorist attacks.

Note that a similar result emerges if we consider instead a change in $\beta$, the weight in the government's objective function on the losses from terrorist attacks. Suppose that the domestic politics are such that the polity has a heightened concern for terrorism, thereby raising the value of $\beta$ in the government's utility function. Then the level of preemption will rise with $\beta$; the response will be more of both kinds of attacks (as before, while more preemption raises the number of volunteers, it reduces the expected return from any particular attack, and hence, more attacks are chosen in equilibrium). As before, the ratio of normal to suicides moves in the same direction as the change in preemption, and the increased public demand for security, while it raises the overall level of terrorism, it reduces the proportion of suicide to normal attacks. ${ }^{7}$

Next, we allow for a change in marginal backlash or the terrorist sympathy parameter, $b$. The impacts of this change are captured in Proposition 2: 
Proposition 2: $\frac{\partial \theta}{\partial b}=0 ; \frac{\partial s}{\partial b} \geq 0 ; \frac{\partial n}{\partial b}>0 ;$ and $\frac{\partial(n / s)}{\partial b}>0$.

Proof: see Appendix.

The amount of preemption is independent of the backlash parameter. There are again two effects stemming from this comparative statics change. An increase in backlash raises recruits, which augment the number of both kinds of terrorist attacks. With recruitment easier, there is a substitution away from suicide attacks toward normal attacks. This follows because enhanced backlash means that suicide attacks are not so necessary to raise recruits. Thus, there is good news - a smaller proportion of suicide attacks - and bad news - more attacks in general.

Finally, we consider the impact of economic opportunities by investigating the effect of the wage, $w$, on terrorist attacks and their mixture.

Proposition 3: $\frac{\partial \theta}{\partial w}=0 ; \frac{\partial s}{\partial w} \leq 0 ; \frac{\partial n}{\partial w}<0 ;$ and $\frac{\partial(n / s)}{\partial w}<0$.

Proof: see Appendix.

The level of preemption does not respond to the wage rate directly. As the wage rises, there are fewer recruits, which, in turn, limit both kinds of terrorist attacks as economic opportunities improve. To counteract this recruitment loss, the terrorist groups will change their mix of normal and suicide attacks, relying more on the latter. Suicide attacks are more productive of recruits, which are sorely needed when opportunity cost is high. 
Governments tread a thin line when responding to the threat of terrorism. Too little preemption can encourage terrorists to heighten their attacks, while too much preemption can lead to backlash. The latter can augment recruitment and increase terrorist attacks. Terrorists can be particularly astute at pushing the government too far so that it overreacts, thereby leading to a backlash and greater support for the terrorists. When terrorists resort to suicide attacks that maim and kill relatively large numbers of innocent individuals, there is a real proclivity on the part of government to respond harshly to such attacks. This tendency is especially strong in a liberal democracy, where a government's legitimacy rests, in part, on its ability to protect its people and their property (Enders and Sandler 2006). In fact, the targeted population will push for an unrestrained preemptive response, which can further alienate an aggrieved population, resulting in more terrorist recruits and attacks.

We present a simple game-theoretic model of terrorism involving three agents: the terrorist leader, the government, and the terrorist supporters. In our two-stage game, the terrorist leader decides attacks while the government determines its preemption. Based on suicide attacks and the level of preemption in the first stage, potential terrorist supporters then decide whether or not to join the group and engage in attacks. Our comparative statics give some interesting findings.

Government is caught in a proverbial bind: the greater its efforts in counterterrorism, attacks indeed will fall, but the proportion of suicide attacks to normal events rises too. This is a consequence of the enhanced backlash effect that comes with suicide attacks. Suicide incidents augment the supply of available recruits to counter the fall in terrorist sympathy. In the case of increased backlash, the terrorist is anticipated to curtail his or her reliance on suicide attacks since antigovernment feelings are already running high. For each of the comparative statics changes, there is a direct effect on the level of attacks and a countervailing effect on the 
proportion of suicide attacks. Suicide terrorism greatly increases the complexity of the appropriate counterterrorism response.

Crucial to these results is the role of backlash effect. Some scholars have argued that terrorism is designed to increase political support for the radical organization; others have argued that terrorism is designed to incite heavy-handed reactions by the government in order to mobilize moderates within the populace. We incorporate both of these effects of terrorist actions on political and economic support for the radical terrorist group, and examine the allocation of resources across a variety of attacks in this context.

The results also suggest a potential explanation for observed variation in the location and targets of suicide attacks. In those environments with severe societal cleavages, those polities in which counterterrorist preemption is more severe and extreme, we are likely to see more frequent use of suicide terrorism (relative to normal attacks) by the radicals. While measuring preemption is challenging, since much is unobservable, we leave this empirical implication for further research. 


\section{Appendix}

We prove the comparative statics propositions first for the interior solution (where $s>0$ and $n>$

0 ). It is useful to note that at any interior solution, it must be the case that $R_{n} \geq 1 . R_{n} \geq 1$ has the interpretation that the terrorists' wage is low relative to the productivity of terrorism.

Lemma: At any interior solution, $R_{n} \geq 1$.

Proof:

We can rewrite the terrorist's problem in terms of the Lagrangian, $L$ :

$L=R(\theta, n, s)-(n+s)+\lambda\left[\Omega\left(\frac{1}{w}\right) P b \theta s-(n+s)\right]$. For an interior solution, we must have

$\frac{d L}{d n}=R_{n}-1-\lambda=0$ and $\lambda \geq 0$. Then $\lambda=R_{n}-1 \geq 0$

Proposition 1. $\frac{\partial \theta}{\partial c}<0 ; \frac{\partial s}{\partial c} \leq 0 ; \frac{\partial n}{\partial c}<0 ;$ and $\frac{\partial(n / s)}{\partial c}<0$

Proof:

The two FOCs are:

$$
\begin{aligned}
-c-\beta R_{\theta} & =0, \\
R_{s}+R_{n}[\Omega P b \theta-1]-\Omega P b \theta & =0,
\end{aligned}
$$

where $\Omega=\Omega(1 / w)$. Taking a total differential of (A1) and (A2) with respect to $c, s$, and $\theta$ and eliminating zero terms (e.g., $R_{\theta s}$ ) give:

$$
\begin{aligned}
-d c-\beta R_{\theta \theta} d \theta & =0, \\
{\left[R_{s s}+R_{n n}(\Omega P b-1)^{2}\right] d s+\left(R_{n} \Omega P b-\Omega P b\right) d \theta } & =0 .
\end{aligned}
$$

This system of differential equations can be rewritten as: 


$$
\left[\begin{array}{cc}
-\beta R_{\theta \theta} & 0 \\
\left(R_{n}-1\right) \Omega P b & R_{s s}+R_{n n}(\Omega P b-1)^{2}
\end{array}\right]\left(\begin{array}{c}
\frac{\partial \theta}{\partial c} \\
\frac{\partial s}{\partial c}
\end{array}\right)=\left(\begin{array}{c}
-1 \\
0
\end{array}\right)
$$

By Cramer's rule, we have:

$$
\frac{\partial \theta}{\partial c}=\frac{\left|\begin{array}{cc}
1 & 0 \\
0 & R_{s s}+R_{n n}(\Omega P b-1)^{2}
\end{array}\right|}{|\Delta|}=\frac{R_{s s}+R_{n n}(\Omega P b-1)^{2}}{-\beta R_{\theta \theta}\left[R_{s s}+R_{n n}(\Omega P b-1)^{2}\right]}=\frac{1}{-\beta R_{\theta \theta}}<0
$$

where $|\Delta|=\left|\begin{array}{cc}-\beta R_{\theta \theta} & 0 \\ \left(R_{n}-1\right) \Omega P b & R_{s s}+R_{n n}(\Omega P b-1)^{2}\end{array}\right|>0$ and $R_{\theta \theta}>0$.

Similarly, we have:

$$
\frac{\partial s}{\partial c}=\frac{-\left(R_{n}-1\right) \Omega P b}{-\beta R_{\theta \theta}\left[R_{s s}+R_{n n}(\Omega P b-1)^{2}\right]} \leq 0
$$

since $R_{n} \geq 1, R_{\theta \theta}>0, R_{n n}<0$, and $R_{s s}<0$.

Recall that

$$
n(s)=\Omega P b \theta s-s .
$$

Taking a derivative of (A8) with respect to $s$, we have:

$$
\frac{\partial n}{\partial c}=\Omega P b\left(\theta \frac{\partial s}{\partial c}+s \frac{\partial \theta}{\partial c}\right)-\frac{\partial s}{\partial c}
$$

which can be rewritten as:

$$
\frac{\partial n}{\partial c}=\frac{\partial s}{\partial c} \frac{n}{s}+\Omega P b s \frac{\partial \theta}{\partial c}<0
$$

where we substituted $\frac{n}{s}=[\Omega P b \theta-1]$ into (A9) via (A8). In (A10), the inequality follows since $\frac{\partial s}{\partial c}<0$ and $\frac{\partial \theta}{\partial c}<0$ 
Finally, we take the partial derivative of $(n / s)$ with respect to $c$ to give:

$$
\frac{\partial(n / s)}{\partial c}=\Omega P b \frac{\partial \theta}{\partial c}<0
$$

Proposition 2. $\frac{\partial \theta}{\partial b}=0 ; \frac{\partial s}{\partial b} \geq 0 ; \frac{\partial n}{\partial b}>0 ;$ and $\frac{\partial(n / s)}{\partial b}>0$.

Proof:

The proof follows the same procedure as that of Proposition 1. We take a total differential of the FOCs in (A1)-(A2) with respect to $b, s$, and $\theta$. By Cramer's Rule, we have:

$$
\frac{\partial \theta}{\partial b}=\frac{\left|\begin{array}{cc}
0 & 0 \\
-\left(R_{n}-1\right) \Omega P \theta & R_{s s}+R_{n n}(\Omega P b-1)^{2}
\end{array}\right|}{|\Delta|}=0,
$$

and

$$
\begin{aligned}
\frac{\partial s}{\partial b}= & \frac{\left|\begin{array}{cc}
-\beta R_{\theta \theta} & 0 \\
\left(R_{n}-1\right) \Omega P b & -\left(R_{n}-1\right) \Omega P \theta
\end{array}\right|}{|\Delta|}=\frac{\beta R_{\theta \theta}\left(R_{n}-1\right) \Omega P \theta}{-\beta R_{\theta \theta}\left[R_{s s}+R_{n n}(\Omega P b-1)^{2}\right]} \\
& =\frac{\left(R_{n}-1\right) \Omega P \theta}{-\left[R_{s s}+R_{n n}(\Omega P b-1)^{2}\right]} \geq 0 \text { since } R_{n} \geq 1, R_{n n}<0, R_{s s}<0 .
\end{aligned}
$$

Differentiating $n(s)$ in (A8) with respect to $b$ yields:

$$
\frac{\partial n}{\partial b}=\Omega P\left(\theta s+b \theta \frac{\partial s}{\partial b}\right)-\frac{\partial s}{\partial b}
$$

since $\frac{\partial \theta}{\partial b}=0$. Rearranging, we have:

$$
\frac{\partial n}{\partial b}=\Omega P \theta s+\frac{\partial s}{\partial b}(\Omega P b \theta s-s) \frac{1}{s} .
$$

Substituting for $n(s)$ in the bracketed term, we get: 


$$
\frac{\partial n}{\partial b}=\Omega P \theta s+\frac{\partial s}{\partial b} \frac{n}{s}>0 .
$$

Finally, we have:

$$
\frac{\partial(n / s)}{\partial b}=\Omega P\left(b \frac{\partial \theta}{\partial b}+\theta\right)=\Omega P \theta>0 .
$$

Proposition 3. $\frac{\partial \theta}{\partial w}=0 ; \frac{\partial s}{\partial w} \leq 0 ; \frac{\partial n}{\partial w}<0 ;$ and $\frac{\partial(n / s)}{\partial w}<0$.

Proof:

We take a total differential of (A1)-(A2) with respect to $w, s$, and $\theta$. By Cramer's rule, we get:

$$
\frac{\partial \theta}{\partial w}=\frac{\left|\begin{array}{cc}
0 & 0 \\
\left(R_{n}-1\right) \Omega^{\prime} P b \theta w^{-2} & R_{s s}+R_{n n}(\Omega P b-1)^{2}
\end{array}\right|}{|\Delta|}=0
$$

and

$$
\frac{\partial s}{\partial w}=\frac{\left|\begin{array}{cc}
-\beta R_{\theta \theta} & 0 \\
\left(R_{n}-1\right) \Omega P b & \left(R_{n}-1\right) \Omega^{\prime} P b \theta w^{-2}
\end{array}\right|}{|\Delta|}=\frac{\left(R_{n}-1\right) \Omega^{\prime} P b \theta w^{-2}}{R_{s s}+R_{n n}(\Omega P b-1)^{2}} \leq 0,
$$

since $R_{n} \geq 1, R_{n n}<0$, and $R_{s s}<0$.

Using the value of $n(s)$ in (A8), we take a partial with respect to $w$ and eliminate $\frac{\partial \theta}{\partial w}=0$ to give:

$$
\begin{aligned}
\frac{\partial n}{\partial w} & =-\Omega^{\prime} P b \theta w^{-2} s+\frac{\partial s}{\partial w}[\Omega P b \theta-1] \\
& =-\Omega^{\prime} P b \theta w^{-2} s+\frac{\partial s}{\partial w} \frac{n}{s}<0,
\end{aligned}
$$

because $n / s=[\Omega P b \theta-1]$.

Finally, we have: 


$$
\frac{\partial(n / s)}{\partial w}=-\Omega^{\prime} P b \theta w^{-2}<0
$$

when we account for $\frac{\partial \theta}{\partial w}=0$.

Corner Solutions: For completeness, we examine the possibility of corner solutions.

First, note that the Inada conditions ( $R_{s}=\infty$ at $s=0$, and $R_{n}=\infty$ at $n=0$ ) on $R(\cdot)$ eliminate the possibility that $s=n=0$ in equilibrium. Second, $s=0, n>0$ cannot be an equilibrium, since whenever $s=0$, the resource constraint is violated: no suicides mean no volunteers from which to recruit (at any level of preemption), and therefore, there cannot be any normal attacks.

The final case is where in equilibrium, $s>0$, and $n=0$. The terrorist group recruits only for suicide missions, and no normal attacks. In this case, there are two possibilities. First, the resource constraint binds with equality, $1=\Omega P b \theta$ (since $n=0$ ), and this occurs if and only if the optimal response for the government is to set $\theta=[\Omega P b]^{-1}$. Recall the government's firstorder condition is $-c-\beta R_{\theta}=0$, yielding $\theta=R_{\theta}^{-1}\left(\frac{-c}{\beta} ; s, 0\right)$. There is no reason that these should be equal generically, making this corner likely to occur with probability zero. Second, if the resource constraint does not bind with equality, then the terrorist's first-order condition reduces to $R_{s}=1$, and the optimal level of $s$ will not change with any of the exogenous parameters. That is, the optimal $s$ does not change with $c, b$, or $w$. 


\section{Footnotes}

1. Bueno de Mesquita and Dixon (2007) consider this effect (they call it "terrorist mobilization") in the context of a game between radicals, moderates, and the government. In their model, the moderates learn about the degree to which the government is hard-line; they endogenize the degree to which government action radicalizes the moderates. Following Rosendorff and Sandler (2004) and de Figueiredo and Weingast (2001), we assume that government action radicalizes moderates. Rosendorff and Sandler (2004) simply model the backlash as an expected loss to the government; de Figueiredo and Weingast (2001) have preemption shift the moderate's ideal point closer to that of the radicals. Here, we make a weaker assumption: in the presence of suicide attacks, government crackdowns increase the number of sympathizers, and, thus, potential terrorists among the population. As to whether these potential terrorists are actually employed by the terrorist organization for attacks is endogenous.

2. In an interesting one-shot game, Arce et al. (2009) also examine the mix of normal and suicide attacks against $n$ potential targets. Their model has two active agents: a terrorist organization (attacker) and a government (defender). They allow for a weakest-link technology but no backlash attacks.

3. We model preemption as reducing the payoff to terrorism generally; we do not model the choice that a government faces in protecting multiple targets, or across types of counterterrorist efforts, such as hardening targets or intelligence gathering. See Enders and Sandler (2004) or Powell (2009).

4. We assume that all volunteers are paid the same wage irrespective of whether they are assigned to a normal or a suicide attack. We make this assumption for the purposes of simplicity and tractability. Permitting the wages to be different will simply shift the equilibrium 
proportions of normal attacks to suicides towards the cheaper option.

5. We also assume that $R_{s}=\infty$ when evaluated at $s=0$, and $R_{n}=\infty$ when evaluated at $n$ $=0$. That is, some terrorist activity is always preferred to none by the terrorist organization.

6. We examine the possibility of corner solutions in the Appendix.

7. The effect of changes in $\beta$ is qualitatively similar and the proof is omitted. 


\section{References}

Arce, D.G. and Sandler, T. (2010) Terrorist spectaculars: Backlash attacks and the focus of intelligence. Journal of Conflict Resolution 54(2), 354-373.

Arce, D.G., Kovenock, D. and Roberson, B. (2009) Suicide terrorism and the weakest link. CESifo Working Paper No. 2753, Category 2: Public Choice. <www.CESifogroup_org/wp>.

Azam, J.P. (2005) Suicide-bombing as inter-generational investment. Public Choice 122(1-2) $177-198$.

Berman, E. and Laitin, D.D. (2008) Religion, terrorism and public goods: Testing the club model. Journal of Public Economics 92(10-11) 1942-1967.

Benmelech, E. and Berrebi, C. (2007) Human capital and productivity of suicide bombers. Journal of Economic Perspectives 21(3) 223-238.

Benmelech, E., Berrebi, C. and Klor, E.F. (2008) Economic conditions and the quality of suicide terrorism. Unpublished paper.

Bloom, M. (2005) Dying to Kill: The Allure of Suicide Terror. New York: Columbia University Press.

Bueno de Mesquita, E. (2005) Conciliation, counterterrorism, and patterns of terrorist violence. International Organization 59(1) 145-176.

Bueno de Mesquita, E. (2008) Terrorist factions. Quarterly Journal of Political Science 3(4) 399-418.

Bueno de Mesquita, E. and Dixon, E.S. (2007) The propaganda of the deed: Terrorism, counterterrorism, and mobilization. American Journal of Political Science 51(2) 364381.

de Figueiredo, R.J.P. and Weingast, B.R. (2001) Vicious cycles: Endogenous political extremism 
and political violence. Unpublished paper.

Enders, W. and Sandler, T. (2004) What do we know about the substitution effect in transnational terrorism? In Research on Terrorism: Trends, Achievements and Failures, edited by A. Silke. London: Frank Cass, 119-137.

Enders, W. and Sandler, T (2006) The Political Economy of Terrorism. Cambridge: Cambridge University Press.

Gupta, D.K. and Mundra, K. (2005) Suicide bombings as a strategic weapon: An empirical investigation of Hamas and Islamic Jihad. Terrorism and Political Violence 17(4) 573598.

Hoffman, B. (2006) Inside Terrorism (Revised Ed.). New York: Columbia University Press.

Jacobson, D. and Kaplan, E.H. (2007) Suicide bombings and targeted killings in (counter-) terror games. Journal of Conflict Resolution 51(5) 772-792.

Jaeger, D.A., Flor, E.F., Miaari, S.H. and Paserman, M.D. (2008) The struggle for Palestinian hearts and minds: Violence and public opinion in the Second Intifada. National Bureau Economic Research Working Paper No. 13956, Cambridge, MA.

Jain, S. and Mukand, S.W. (2004) The economics of high-visibility terrorism. European Journal of Political Economy 20(2) 479-494.

Kaplan, E.H., Mintz, A., Mishal, S. and Samban, C. (2005) What happened to suicide bombings in Israel? Insights from a terror stock model. Studies in Conflict and Terrorism 28(3) $225-235$.

Mickolus, E.F., Sandler, T., and Murdock, J.M. (1989) International Terrorism in the 1980s: A Chronology of Events, 2 vols. Ames, IA: Iowa State University Press.

Pape, R.A. (2005) Dying to Win: The Strategic Logic of Suicide Terrorism. New York: Random House. 
Pedahzur, A. (2005) Suicide Terrorism. Malden, MA: Polity Press.

Powell, R. (2007) Defending against terrorist attacks with limited resources. American Political Science Review 101(3) 527-541.

Rosendorff, B. P. and Sandler, T. (2004) Too much of a good thing? The proactive response dilemma. Journal of Conflict Resolution 48(5) 657-671.

Sandler, T. and Lapan, H.E. (1988) The calculus of dissent: An analysis of terrorists' choice of targets. Synthese 76(2) 245-261.

Wintrobe, R. (2006) Extremism, suicide terror, and authoritarianism. Public Choice 128(1) 169195. 